\title{
POLYOXYMETHYLENE IN COMETARY DUST: LABORATORY TESTS
}

\author{
D.C. BOICE, D.W. NAEGELI, and W.F. HUEBNER \\ Southwest Research Institute \\ P.O. Drawer 28510 \\ San Antonio, TX 78228-0510 \\ USA
}

\begin{abstract}
We have investigated the stability of gas-phase formaldehyde oligomers and its implications for cometary science. Our experiments indicate that when a formaldehyde-methanol solution is vaporized in the mass spectrometer, high molecular mass POM species (45, 61, 75, $91,105,121,135,151,165 \mathrm{amu}$ ) exist in the gas phase in the temperature range $473 \mathrm{~K}$ to $773 \mathrm{~K}$. These laboratory results complement our previous experiments using a formaldehyde-water solution and indicate that formaldehyde oligomers are stable in the gas phase up to at least 6 monomeric units in length. Methanol is important in the end-capping process of the oligomers, leading to increased stability and a richer mass spectrum when compared to the formaldehyde-water solution. The results are consistent with mass spectra obtained by the Giotto PICCA instrument exhibiting alternating 14-16 amu mass peaks.
\end{abstract}

\section{Introduction}

One of the surprises of the recent spacecraft encounters with Comet Halley was the discovery of the "CHON" particles. While the exact nature of the organic constituents of CHON remains uncertain, polyoxymethylene (POM) is likely to be an important constituent. We have previously proposed a schematic comet dust particle composed of silicate grains, carbonaceous material, and complex organic molecules including formaldehyde oligomers (Huebner et al., 1987). The affinity of these oligomers for silicate surfaces binds the grains and holds the particle together. As the particles drift away from the nucleus, solar heating causes them to fragment on time scales related to the decomposition properties of the oligomers. This has also been suggested by Boenhardt et al. (1990). In addition, POM and other semivolatile compounds are slowly released from the grains and contribute to the distributed sources of $\mathrm{CO}, \mathrm{H}_{2} \mathrm{CO}, \mathrm{CH}_{n}(n=1,2)$, and other coma species. This grain picture is consistent with many observations of Comet Halley (including the mass spectra obtained with the PICCA instrument) as pointed out by Huebner and Boice (1989) and Boice et al. (1990).

\section{Laboratory Experiments and Results}

Experimental work on the identification of vapor phase products of polyoxymethylene has been carried out using a mass spectrometer equipped with a variable temperature sample probe. A preliminary description of the laboratory study and first results using dry paraformaldehyde (solid polyoxymethylene) and a formaldehyde-water solution have been given by Boice et al. (1989). A brief summary is given below.

It is well known that the principal product of paraformaldehyde decomposition at room temperature and above is formaldehyde gas. Previous studies (Walker, 1964) have shown that when paraformaldehyde is heated to $423 \mathrm{~K}$, the evolved gas consists mainly of formaldehyde monomer.

\section{5}

A.C. Levasseur-Regourd and H. Hasegawa (eds.), Origin and Evolution of Interplanetary Dust, 265-268. ( 1991 Kluwer Academic Publishers, Printed in Japan. 
However, recent results obtained by Moller and Jackson (1989) indicate that polymeric forms of formaldehyde are present and stable in the gas phase at temperatures as low as $300 \mathrm{~K}$. Our initial work (Boice et al., 1989) extended this result to higher temperatures and masses, and implied the existence of an oligomer, 5 monomeric units in length. POM fragments were also produced by Moore and Tanabe (1990) during $700 \mathrm{KeV}$ proton sputtering and by Mahaffy (1989) with $4 \mathrm{KeV}$ $\mathrm{Cs}^{+}$bombardment. These studies, performed by a variety of methods, all yield results consistent with the stability of ionic POM fragments in the gas phase, with a characteristic pattern separating mass peaks of alternating 14-16 amu.

In the present experiments, we choose to investigate formaldehyde-methanol solutions for two reasons. Recent work by Busca et al. (1987) shows that formaldehyde, in the form of dioxymethylene absorbed on metal oxide surfaces, undergoes a disproportionation reaction forming formate and methoxide groups, probably via a Cannizzaro-type mechanism. It is possible that the Cannizzarotype reaction produces some formic acid and methanol from formaldehyde adsorbed on the surface of comet dust particles. Additionally, methanol provides $\left(\mathrm{CH}_{3}\right)$-groups for end-capping polyoxymethylene, a likely circumstance in comet dust rich in carbonaceous material.

The mass spectra were obtained using a Finnigan model 3300 mass spectrometer with a CDS model 120 pyroprobe. The pyroprobe has a platinum ribbon to hold the sample and can be heated to various temperatures in a few milliseconds. In the actual experiments, the samples were heated to temperatures ranging from $473 \mathrm{~K}$ to $773 \mathrm{~K}$. The samples consisted of a solution of $30 \%$ formaldehyde in methanol, prepared by refluxing a mixture of paraformaldehyde and methanol in a thick-walled glass vessel and heating to $373 \mathrm{~K}$ for about 30 hours.

In our previous study using the formaldehyde-water solution, mass peaks were observed at 47 , $61,77,91,107,121$, and 137 amu. While these results gave the characteristic spacing of the mass peaks observed in the PICCA spectra, the peaks at 47, 77, and 107 were shifted by 2 amu to higher masses. Furthermore, the experimental mass spectra were sparce, with peaks centered at the above masses and very little in between.

For the formaldehyde-methanol solution, mass peaks were observed at $45,61,75,91,105,121$, 135,151 , and 165 amu as shown in Figure 1. Probable identification of the ions corresponding to these masses (as well as those of the formaldehyde-water solution) are listed in Table 1. This sequence of mass peaks precisely matches that observed in the PICCA spectrum reported by Korth et al. (1986) and Mitchell et al. (1987). The mass distribution shows considerably more detail than that of the formaldehyde-water mixture, with many smaller peaks surrounding the major ones. We note that all of the structure in the mass spectrum results from molecules containing only combinations of $\mathrm{H}, \mathrm{C}$, and $\mathrm{O}$. A change in relative peak intensities is also apparent, with higher mass species being relatively more abundant in the formaldehyde-methanol solution. It is preliminary to claim that the observed mass spectrum has been reproduced, but continued analysis of the laboratory data will give likely candidates for some of the satellite peaks that may account for the broadening of the observed PICCA mass peaks.

In our previous study, high concentrations of water were found to be important in the endcapping process that stabilizes these species. This suggests that the proton affinity of POM-related oligomers is rather high as all mass peaks are consistent with protonated species. End-capping by methyl groups also promotes stability of the resulting molecule. These experiments were repeated with a Gas Chromatograph (model 5890)/Mass Selective Detector (model 5970) instrument to support the above results. A relatively neutral column of about 5 meters in length was used. The results obtained with the formaldehyde-water mixture were inconclusive as none of the higher-mass peaks were found in the spectra. It was suggested that the high-mass species either precipitated onto the column wall or decomposed during the long journey through the column. In contrast, gas chromatography of the formaldehyde-methanol solution yielded several high-mass peaks for neutral species roughly corresponding to those in the ionic mass spectra. Our preliminary conclusion is that end-capping polyoxymethylene chains with methanol-related groups leads to relatively stable neutral gas-phase species. 


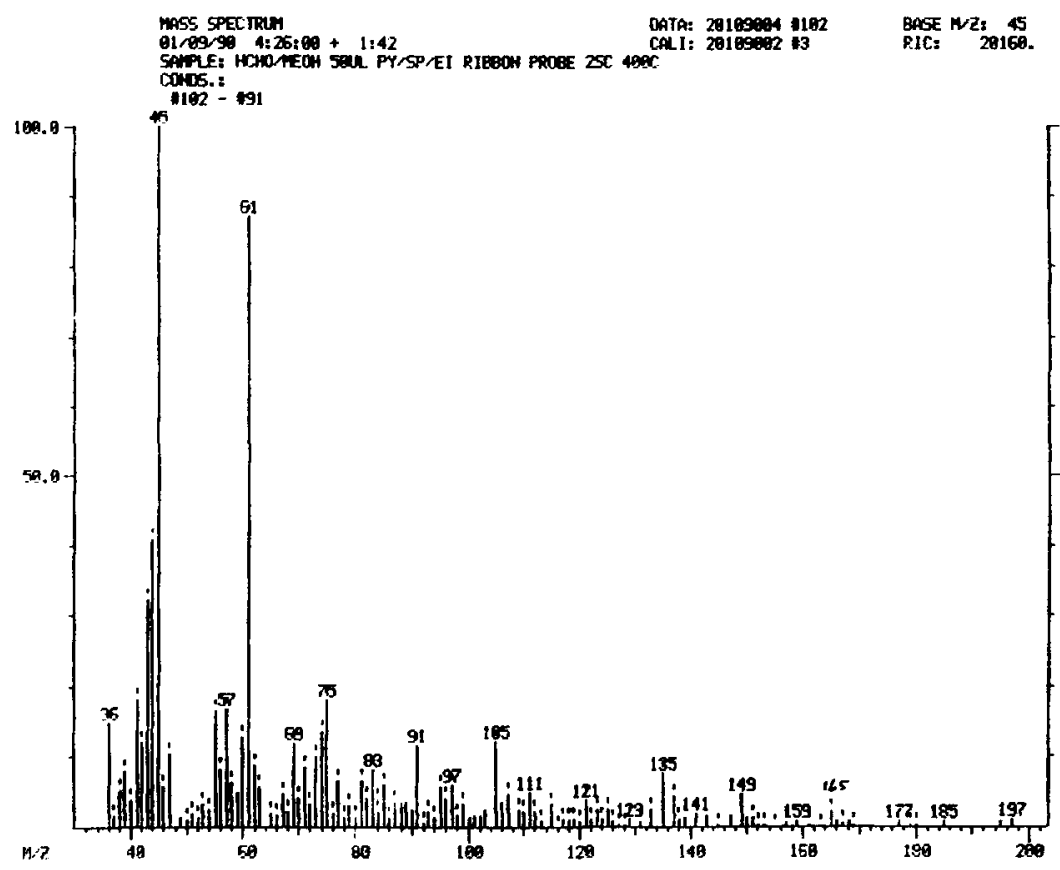

Figure 1. Mass spectrum of the formaldehyde-methanol solution heated to $673 \mathrm{~K}$ and using a $20 \mathrm{eV}$ electron source in the mass spectrometer. Note the mass peaks at $45,61,75,91,105,121,135$, 151 , and $165 \mathrm{amu}$, and the many satellite peaks surrounding the major peaks.

TABLE 1. Mass spectra species identification

\begin{tabular}{ccc}
\hline Mass & Probable POM-related species & Designation of ion fragment \\
\hline 45 & $\mathrm{CH}_{3}-\mathrm{O}-\mathrm{CH}_{2}^{+}$ & Methyl ether \\
47 & $\mathrm{HO}-\mathrm{CH}-\mathrm{OH}^{+}$ & Methylene glycol \\
61 & $\left(\mathrm{CH}_{2}-\mathrm{O}\right)_{2}-\mathrm{H}^{+}$ & POM dimer glycol \\
& $\mathrm{H}-\left(\mathrm{CH}_{2}-\mathrm{O}\right)_{2}^{+}$ & POM dimer methyl ether \\
75 & $\mathrm{CH}_{3}-\left(\mathrm{O}-\mathrm{CH}_{2}\right)_{2}^{+}$ & POM fragment methyl ether \\
77 & $\mathrm{HO}-\mathrm{CH}_{2}-\mathrm{O}-\mathrm{CH}_{-} \mathrm{OH} \mathrm{H}^{+}$ & Protonated POM fragment \\
91 & $\left(\mathrm{CH}_{2}-\mathrm{O}\right)_{3}-\mathrm{H}^{+}$ & POM trimer glycol \\
& $\mathrm{H}^{+}\left(\mathrm{CH}_{2}-\mathrm{O}\right)_{3}^{+}$ & POM trimer methyl ether \\
105 & $\mathrm{CH}_{3}-\left(\mathrm{O}-\mathrm{CH}_{2}\right)_{3}^{+}$ & POM fragment methyl ether \\
107 & $\mathrm{HO}-\left(\mathrm{CH}_{2}-\mathrm{O}\right)_{2}-\mathrm{CH}-\mathrm{OH}^{+}$ & Protonated POM fragment \\
121 & $\left(\mathrm{CH}_{2}-\mathrm{O}\right)_{4}-\mathrm{H}^{+}$ & POM tetramer glycol \\
& $\mathrm{H}-\left(\mathrm{CH}_{2}-\mathrm{O}\right)_{4}^{+}$ & POM tetramer methyl ether \\
135 & $\mathrm{CH}_{3}-(\mathrm{O}-\mathrm{CH})_{4}^{+}$ & POM fragment methyl ether \\
137 & $\mathrm{HO}-\left(\mathrm{CH}_{2}-\mathrm{O}\right)_{3}-\mathrm{CH}-\mathrm{OH}^{+}$ & Protonated POM fragment \\
151 & $\mathrm{H}^{+}\left(\mathrm{CH}_{2}-\mathrm{O}\right)_{5}^{+}$ & POM pentamer methyl ether \\
165 & $\mathrm{CH}_{3}-(\mathrm{O}-\mathrm{CH})_{5}^{+}$ & POM fragment methyl ether \\
\hline
\end{tabular}




\section{Summary}

The results of this research indicate that ionic POM-related oligomers are stable in the gas phase, up to at least 6 monomeric units in length. Methanol is important in the end-capping process for the stability of the oligomers, and it appears to lead to species that are more stable than those formed in formaldehyde-water mixtures.

The mass spectra of the formaldehyde-methanol solution are consistent with the maxima of the mass distributions obtained by the PICCA instrument in Comet Halley. Futhermore, these mass spectra show considerable detail with many small peaks surrounding the major ones. Continued analysis of these data will give likely candidates for some of the satellite peaks that may account for the broad PICCA mass peaks.

The presence of POM as one constituent in the complex organic mixture associated with cometary dust is consistent with many observations of comets and with several laboratory studies.

\section{Acknowledgements}

This study was supported by the Internal Research Program at Southwest Research Institute and the NASA Planetary Atmospheres Division.

\section{References}

Boenhardt, H., Fechtig, H., and Vanysek, V. (1990) 'The possible role of organic polymers in the structure and fragmentation of dust in the coma of comet P/Halley,' Astron. Astrophys. 231, 543-547.

Boice, D.C., Naegeli, D.W ., and Huebner, W.F. (1989) 'Physico-chemical properties of formaldehydeice-dust mixtures,' Proceedings of an International Workshop on Physics and Mechanics of Cometary Materials, ESA SP-302, 83-88.

Boice, D.C., Huebner, W.F., Sablik, M.J., and Konno, I. (1990) 'Distributed coma sources and the $\mathrm{CH}_{4} / \mathrm{CO}$ ratio in comet Halley,' Geophys. Res. Lett. 17, in press.

Busca, G., Lamotte, J., Lavalley, J.-C., and Lorenzelli, V. (1987) 'FT-IR study of the adsorption and transformation of formaldehyde on oxide surfaces,' J. Am. Chem. Soc. 109, 5197-5202.

Huebner, W.F. and Boice, D.C. (1989) 'Polymers in comet comae,' in J.H. Waite, Jr., J.L. Burch, and R.L. Moore (eds.), AGU Monograph 54, pp. 453-456.

Huebner, W.F., Boice, D.C., Sharp, C.M., Korth, A., Lin, R.P., Mitchell, D.L., and Reme, H. (1987) 'Evidence for first polymer in Comet Halley: Polyoxymethylene,' Symposium on the Diversity and Similarity of Comets, ESA SP-278, 163-168.

Korth, A. et al. (1986) 'Mass spectra of heavy ions near comet Halley,' Nature 321, 335-336.

Mahaffey, P. (1989) 'SIMS of polyoxymethylene and questions of cometary dust composition,' preprint.

Mitchell, D.L. et al. (1987) 'Evidence for chain molecules enriched in carbon, hydrogen, and oxygen in comet Halley,' Science 237, 626- 628.

Moller, G. and Jackson, W.M. (1989) 'Laboratory studies of polyoxymethylene: application to comets,' Icarus, in press.

Moore, M.H. and Tanabe, T. (1990) 'Mass spectra of sputtered polyoxymethylene - implications for comets,' Astrophys. J. Lett., in press.

Walker, J.F. (1964) Formaldehyde, Reinhold Publishers, New York. 